\title{
Bloom Where You're Planted: Spreading the Seeds of Leader in Me Everywhere
}

\author{
Carol Bennett \\ Brigham Young University-Hawaii
}

\begin{abstract}
There are over 4,000 schools in the Leader in Me process worldwide. This study explored the Leader in Me process in schools specifically in Hawaii, to discover the effect on academic achievement, as well as, behavior according to participating school principals' perceptions. This study adds to the sparse literature exploring the Leader in Me process. Teacher satisfaction, greater communication and collaboration, improved student behavior, greater parent involvement, more feelings of empowerment, and positive school environment were all strong indicators. As has been noted in similar studies, greater time in the Leader in Me process indicates more positive results.
\end{abstract}

Keywords: educational reform, school improvement, school effectiveness, leadership, social emotional learning, principal perceptions, collaboration, empowerment, Leader in Me, Seven Habits

\section{INTRODUCTION}

Research has indicated that the Leader in Me process has shown success in raising academic scores and reducing behavioral referrals in multiple schools in the US mainland and several other countries. The Leader in Me website identifies the associated research.

Since 2010, the empirical evidence for Leader in Me has been growing rapidly and there are now over 30 academic research studies which have evaluated the effectiveness of Leader in $\mathrm{Me}$ and proved its impact. A full range of experimental methods have been used, from sophisticated quantitative analysis of statewide data, to intensive qualitative studies that analyzed interview data from dozens of educators, families, and students. In addition, nearly all of the studies were reviewed by a peer or academic advisory group before release, and all studies were conducted by researchers who had full intellectual freedom in the analysis and results. (www.leaderinme.org)

Research that demonstrates this impact includes the University of Michigan's College of Education, which released the findings from two separate quasi-experimental studies showing positive impacts to student disciplinary referrals and attendance in Leader in Me schools. One report focused on disciplinary rates and attendance in Missouri and the other on disciplinary rates in Florida. The findings are the strongest empirical evidence of the effectiveness of the Leader in Me process to date. Both studies followed the strict evidence standards required by What Works Clearinghouse (WWC) and the Collaborative of Academic, Social and Emotional Learning (CASEL). 
Below are key findings from the two reports:

- Leader in Me schools in Missouri had 42 percent fewer discipline incidence than predicted by pre-Leader in Me performance and matched controls. Had Leader in Me schools not participated in the process, they would have had significantly more discipline incidence.

- Leader in Me schools in Missouri who left the Leader in Me process experienced a significant decline $(\mathrm{P}<0.0001)$ in school attendance compared to schools that still remain in the Leader in $\mathrm{Me}$ process and matched control schools.

- Leader in Me schools in Missouri that have participated in the process since the launch of Leader in Me 3.0, experienced significantly increased attendance $(\mathrm{P}=0.007)$.

- An analysis of Florida Leader in Me schools compared with matched control schools revealed a 23 percent improvement in disciplinary incidence for Leader in Me schools.

In March 2018, the Collaborative for Academic, Social, and Emotional Learning (CASEL) endorsed Leader in $\mathrm{Me}$ as a "CASEL SELect" program (their program-certification title). This designation is notable as it identifies Leader in $M e$ as an approved social and emotional learning (SEL) approved program. Leader in Me had to meet an intensive analysis by CASEL reviewers to determine that the program followed their high quality and evidence-based criteria.

CASEL is the leading authority in the advancement of SEL in education. CASEL's focus on empirical evidence and extensive collaborative efforts has made it the trusted source for educational administrators and policymakers seeking guidance on effectively advancing social and emotional learning in their $\mathrm{K}-12$ students. CASEL has been reviewing SEL programs for over a decade through an increasingly rigorous selection process.

This is an important designation because as a CASEL SELect program, Leader in Me will be included in the CASEL Program Guide: Preschool and Elementary Edition. "The CASEL Guides provide school districts with a direction in determining which SEL program best fits their students' needs" (Leader in $\mathrm{Me})$.

This body of research is impressive, yet to date, no studies have been conducted to review the effects of the Leader in Me process specifically on schools in Hawaii. Of the over 4,000 schools in the Leader in $M e$ process worldwide, currently there are ten elementary schools which have officially been designated as in the Leader in Me process in Hawaii. The focus of this study was to explore the Leader in Me process in schools in Hawaii, to discover if it has had a positive effect with academic achievement indicated by state test data in reading, math, and science, as well as, improved behavior according to participating school principals' perceptions of the number of behavior referrals. Principals' perceptions of overall satisfaction and additional indications of school improvement were also identified.

Schools in Hawaii are relatively new to the Leader in Me process. Eight of the ten schools have only become Leader in Me schools in the past year or two. With over 4,000 schools worldwide involved in the Leader in Me process, there has been a growing interest in the success of schools involved in this process. Becoming a Leader in Me school costs are substantial and significant time must be designated for the training. It is important to faculty, parents, the community, as well as other potential Leader in Me schools to examine the effect of this process. The potential benefits of this study are worthwhile because it is important for the district and other schools to determine if the Leader in Me process is beneficial to the students and schools. These findings could greatly impact principals' decisions to become involved in the professional development and financial commitment needed in becoming a Leader in Me school. These findings further add to the body of research being accumulated on the Leader in Me process. 


\section{REVIEW OF RELATED RESEARCH}

Creating a safe school environment with data-driven decisions structured on evidenced-based practices has been shown to have positive effects on clear and measurable outcomes (Simonson et al., 2008). When schools implement effective policies and positive behavioral interventions, school discipline is reduced (Unal \& Cukur, 2011). Further, addressing behavior problems that impede student learning can make a huge difference in school success, especially when emphasis is put on building teacher and student rapport. This type of collaborative culture can promote trust and inspire commitment to reach common goals which creates a successful learning environment (Darling-Hammond, 1998). Michael Fullan (2010) advocates for schools to become powerful learning organizations in the 21st century which requires real work from both students and teachers (Warren et al, 2006). Effective and consistent school leadership has been shown to pose a lasting impact on the culture within a school and results in greater school achievement (Beteille, Kalogrides, \& Loeb, 2012). Walters, Marzano, and McNulty (2003) reported on 30 years of research on the effect of leadership on student achievement. Their meta-analysis of nearly every study conducted since the 1970's that examined the effect of leadership on academics involved more than 5,000 studies, with 70 meeting the study's strict requirements. The data from the meta-analysis demonstrate that there is a substantial relationship (or correlation) between leadership and student achievement.

More than two dozen independent studies have indicated that the Leader in Me process has shown positive results in numerous areas. According to the current Leader in Me website, "Objective evidence of Leader in Me effectiveness has been steadily growing since 2010. To date, over 30 independent, academic research studies have evaluated-and validated-positive impacts of Leader in Me across a wide variety of areas." (2018) The Leader in Me website further describes how students' behavior is affected in Leader in Me schools:

Leadership is a choice, and for Leader in Me students their leadership choices are demonstrated most clearly through self-discipline. Negative interactions with peers, outbursts in class, and disrespect of teachers, that rise to the level of a discipline referral are often a lack of self-discipline. As students throughout Leader in Me schools learn the skills of personal and interpersonal leadership, their self-discipline increases and school wide discipline referrals inevitably decline.

In a mixed methods study on the Leader in Me process implementation in elementary schools in Louisiana, data was collected over a five-year period of time. Cummins's (2015) analysis showed increased student achievement and improved behavior according to data collected and teacher perceptions. The researcher concluded that cultivating leadership skills positively impacted elementary students' behavior, efficacy, and overall achievement.

In several other elementary schools in Virginia, Pennsylvania, Indiana, and Georgia, Evan's (2014) research analysis concluded that implementation of the Leader in Me process in schools led to positive gains in school culture, leadership development, and personal growth. Several STATIS audits noted that students performed with greater on-task behavior. Additionally, student disciplinary referrals declined by $60 \%$. The study concluded that the Leader in Me process develops students into transformational leaders.

The University of Michigan's College of Education (2018) released findings from two separate quasiexperimental studies of Leader in Me schools that found positive impacts in regards to student disciplinary referrals. One of the reports focused their analysis on disciplinary rates in the state of Florida. While the other looked at a reduction in disciplinary rates and improved attendance in the state of Missouri. The Leader in Me website states that these findings are the strongest empirical evidence of effectiveness to date of Leader in Me schools. Especially notable with these two studies is that they followed strict evidence standards required by What Works Clearinghouse (WWC) and the Collaborative of Academic, Social and Emotional Learning (CASEL). 
In 2018, White conducted important research in the state of Missouri. The state had 119 Leader in Me schools and 1,134 non-Leader in Me schools. The focus of the study was exploring the causal effect of the Leader in $\mathrm{Me}$ process on attendance rates and disciplinary outcomes. The researchers used publicly available attendance and disciplinary data. The results of the study indicated that the Leader in Me process led to significant decreases in the rate of disciplinary incidents (by about $60 \%$ for an average sized school). Further, the Leader in Me process had a marginally significant effect on attendance rates, increasing attendance by $0.6 \%$.

Academic results have also been shown to indicate positive trends. Lynn (2015) conducted quantitative research involving a Leader in Me school in San Diego looking at language arts proficiency among 645 third grade students. The researcher separated the students into two groups: those who were proficient in the 7 Habits based on assessment and those who scored less than proficient. The data, based on the results of the t-test and with $95 \%$ confidence, revealed that there was a notable difference in the language arts standards between students that performed proficiently in applying the 7 Habits compared to the ones that were less proficient in applying the 7 Habits.

Additionally, findings from a prestigious peer-reviewed research study in the October (2017) issue of the Florida Association of Teacher Educator's Journal examined the statewide science scores of more than 50 schools in Florida who were implementing The Leader in Me process. Schilling (2018) conducted a quasi-experimental study to discern long-term impacts on behaviors and disciplinary interventions. The experimental group included 77 Leader in Me schools, while the control group consisted of 1,932 nonLeader in Me schools. The Leader in Me schools experienced a 13\% decline in disciplinary interventions compared to the non-Leader in Me control group schools. Interestingly, the analyses revealed clear and compelling alignment between the fundamental leadership components within The Leader in Me process and the best practices for effective science teaching as promoted by the Next Generation Science Standards.

Similarly, research from Texas A\&M University Commerce (2015) compared fifth grade math and English language arts test scores from Leader in Me schools and non-Leader in Me schools. The researcher's analysis revealed implementation of the Leader in Me process was an important factor in academic performance, with Leader in Me schools performing significantly better than non-Leader in Me schools on both math and English language arts scores.

Test scores are not the only indication of the success of Leader in Me schools, as shown in Tidd's (2016) qualitative research conducted through Walden University with teachers, administrators, and other staff members from three schools in the southeastern region of the United States. Surveys and personal interviews were used to identify the Leader in Me process's impact on student motivation and peer relationships. The results of the study confirmed that key elements of The Leader in Me process does indeed increase student motivation and promote positive peer interactions.

In 2016, Swanter, from Lamar University, conducted a phenomenological case study to understand the influence of implementing at a Title I elementary school. Research involved a series of focus-group interviews with teachers, students, and other community stakeholders. Conclusions from the study indicated that students had taken ownership of the habits and used them proactively to be in control of their actions. Additionally, teachers felt empowered by the process and took on greater leadership opportunities due to the self-confidence they had gained through implementing the Leader in Me process.

John Hopkins University research conducted a "case study" evaluation of the Leader in Me at two schools differing in geographic location and demographic characteristics (Ross 2012.) Teachers, principals, and parents all gave examples illustrating how student behavior had improved. Teachers all agreed that the Leader in Me process had made teaching easier and more enjoyable. The study also showed that students' self-confidence and motivation had improved greatly. The strongest consensus from those involved in the study was that the Leader in Me process had positively improved school climate. The case studies revealed highly enthusiastic and collaborative school communities that were experiencing many benefits from the Leader in Me process.

Other studies have indicated the positive results from implementing the Leader in Me process in their schools. Schools such as Dewey Elementary in Quincy, Illinois are identifying numerous benefits from 
being involved in this process. At Dewey, tardiness dropped by 35 percent. The number of parents attending PYA (parent and teacher association) meetings more than doubled. Discipline referrals dropped by 75 percent. Their improvements were noted in academics as well. Within two years the percentage of students passing end-of-grade reading tests jumped from 57.4 percent to 89.7 percent and the percentage of students passing math jumped from 77.4 up to 100 (Covey, 2014). These types of improvements in academics, behavior, motivation, parental involvement, and overall attitudes from both students and teachers have been identified as positive effects from implementing the Leader in Me process.

\section{RESEARCH METHODOLOGY}

For this study, both qualitative and quantitative data were collected to provide a more accurate analysis of the impact of Leader in Me process on schools in Hawaii. State test scores for three different subject tests were used as well as in-person interviews with principals from each of the Leader in Me schools in Hawaii.

\section{Qualitative Analysis}

Qualitative data were collected from in-depth, semi-structured, face-to-face interviews with principals from each of the ten schools. These interviews were personally recorded and later transcribed for further analysis. Through gathering data in the principals' own words, clearer interpretation of their perspectives were identified. The interviews employed open-ended questions to document the principals' experiences and perspectives since beginning the Leader in Me process. This qualitative data was further analyzed for emergent themes to explore the perceptions of principals in schools in Hawaii using the Leader in Me process.

\section{Emergent Themes}

Numerous themes emerged from analyzing the data. The predominant themes from the qualitative data included positive school climate, teacher and student empowerment, fewer behavior referrals, greater teacher collaboration, and more parental involvement. Many of these themes had similarities in minor themes of collegiality, common language, whole school process, improved environment, and improved attitudes. These were incorporated into the following major themes for simplicity of display.

\section{Positive School Climate}

The principals at each of the ten schools commented on how their whole school climate had been positively improved since implementing the Leader in Me process. Several mentioned that they had conducted a quality school survey which indicated that the teacher satisfaction had increased significantly. One principal described how everyone in the school was speaking the (Leader in Me) language and that it had happened so naturally. Using this common language had unifying effects on the school community. Students were making friends from a different culture and showing an increased sense of confidence. Several principals commented on how the physical look changed within their schools as the walls and hallways started to reflect the positive messages of the 7 Habits. Leadership murals were being designed by teachers, students, and parents and implemented within the school house. In addition, there was an overall school clean-up which brought a renewed sense of pride in the school, from both staff and students. 
TABLE 1

PRINCIPAL PERCEPTIONS OF IMPROVEMENTS IN POSITIVE SCHOOL CLIMATE

\begin{tabular}{|l|}
\hline Teachers will tell you they feel better. \\
\hline (We) feel there is more collegiality. \\
\hline Staff are happier. Students are happier. I am less stressed. \\
\hline Now I say I love my job. I love the people that I work with and I love my students. \\
\hline It was so inspirational. It was amazing. Everybody was on the same page. \\
\hline $\begin{array}{l}\text { Everybody knows what the goal in mind is then everybody works together. Our staff is } \\
\text { applying it to their own personal lives. That part is amazing. }\end{array}$ \\
\hline
\end{tabular}

\section{Teacher and Student Empowerment}

Every principal interviewed commented favorably about the empowerment that teachers and students had experienced since beginning the Leader in Me process. Teachers experienced a renewed sense that they could achieve greater success in helping students reach their maximum academic level of performance. Additionally, teachers were excited to experience sharing their ideas in advocating for needed changes in the school culture. They felt stronger and more confident in using their voices for improving curriculum and other school policies. This positive self-confidence in their own abilities had a contagious effect on other teachers and ultimately spread to the students and even the parents. It was as if everyone within the school environment developed a new energy and excitement for learning. The more the excitement grew, the more support the school gained from the community and businesses within the school area.

Along with this empowerment, students became more involved in the dynamics of the school. Through becoming increasingly aware of their grades with data tracking notebooks and setting goals they refer to as WIGs ("Wildly Important Goals") for their academic performance, students started showing pride in their successes and their improvements. Principals noted that students were demonstrating that they felt empowered to take responsibility for their learning. Students began to see the connection between their own choices and behavior and the outcome. This sense of responsibility was a contagious thing which quickly spread throughout many classrooms. Students felt empowered to initiate clubs which were enrichment activities for them that went beyond normal school offerings. One school noted that all of their assemblies were run, written, produced, led, organized, and completely set up by students. 


\section{TABLE 2 \\ PRINCIPAL PERCEPTIONS OF TEACHER AND STUDENT EMPOWERMENT}

\begin{tabular}{|c|}
\hline Both students and teachers were becoming leaders in their lives. \\
\hline People here feel empowered to take leadership roles and begin great things for others. \\
\hline $\begin{array}{l}\text { Our core philosophical belief is that everyone can be a leader. Students are provided } \\
\text { opportunities to have leadership roles regardless of what an individualized education plan } \\
\text { says, regardless of their economic backgrounds, regardless of their perceived beliefs of } \\
\text { their gifts of things they are capable of doing. }\end{array}$ \\
\hline $\begin{array}{l}\text { [Improvement] definitely in the confidence that our students and the clientele that we have, } \\
\text { now garner. It is just amazing. }\end{array}$ \\
\hline $\begin{array}{l}\text { I think what I like best is just down at the student level, an increased sense of confidence in } \\
\text { just our kids. }\end{array}$ \\
\hline $\begin{array}{l}\text { Everybody knows what the goal in mind is then everybody works together. Our staff is } \\
\text { applying it to their own personal lives. That part is amazing. }\end{array}$ \\
\hline $\begin{array}{l}\text {... focus on student-led conferencing and starting to see the changes in academics. Students } \\
\text { have a sense of confidence. }\end{array}$ \\
\hline We "leaderize" students. \\
\hline This year is really about empowerment: teacher and student empowerment. \\
\hline $\begin{array}{l}\text { The empowerment that it has given to students: it's given them a voice and it's not one of } \\
\text { arrogance or entitlement. The kids serve. Kids have actually built clubs around solving } \\
\text { school problems. }\end{array}$ \\
\hline Some of my third graders could run a meeting better than I've seen adults do. \\
\hline $\begin{array}{l}\text { What we like best about Leader in Me, I think the empowering of the staff and the s } \\
\text { People are finding their voice. }\end{array}$ \\
\hline
\end{tabular}

\section{Fewer Behavior Problems}

In each of the interviews, principals were quick to mention how their school's behavior problems had declined since beginning Leader in Me. Even in the schools that had few behavior problems before becoming a Leader in Me school, the principals still agreed that behavior had improved as students began learning the habits. One school's behavior referrals were cut in half their first year in the Leader in Me process (see Figure 3.) While another school dropped from 127 behavior referrals before becoming a Leader in Me school to a mere 18 behavior referrals after their first year implementing Leader in Me (see Figure 3.) At least three of the principals discussed how teacher and staff behavior had also improved with fewer incidences of disagreements that escalated to the principal's office. Gossip and backbiting among the staff had stopped. Several principals described positive changes in behavior as the greatest improvement since becoming Leader in Me schools. This claim of fewer behavior referrals has been supported by numerous other Leader in Me studies (Coffey, 2018; Schilling, 2018; White, 2018.) 


\section{TABLE 3 \\ PRINCIPAL PERCEPTIONS OF FEWER BEHAVIOR PROBLEMS}

\begin{tabular}{|l|}
\hline Where are all the kids, because there are no referrals? \\
\hline There is definitely positively affected student referral data. \\
\hline $\begin{array}{l}\text { Behavior problems went down dramatically. The year before we started, there were } 127 \text { and } \\
\text { then the first year of Leader in Me, they went down to } 18 .\end{array}$ \\
\hline It's a totally different environment. \\
\hline The teachers are noticing a difference in our students. \\
\hline Teachers are very good at addressing and teaching behaviors in their classrooms. \\
\hline You can see it definitely in behavior. There's an increased sense of confidence in our kids. \\
\hline We've made progress in focusing on students' behaviors and attitudes. \\
\hline $\begin{array}{l}\text { Our behavior referrals have gone down. Students have an easier time reflecting on their } \\
\text { mistakes, if they do occur, and can find instances where a habit was not practiced which led } \\
\text { to the referral. }\end{array}$ \\
\hline Teachers and staff are actually getting along better and working together in harmony. \\
\hline
\end{tabular}

Greater Teacher Collaboration

Principals especially appreciated the way that the Leader in Me had encouraged greater collaboration among their staff. Teachers felt they were more on the same page when it came to accomplishing their school mission and goals. Teachers were sharing lesson integration ideas using the habits. Additionally, several schools had begun to hold regular data team meetings where grade levels analyzed their students' scores and worked together to plan for remediation or challenge for the students through their WIGS (wildly important goals.) Principals shared that teachers were actually collaborating with other school staff to encourage all who were working together for each student's success. One principal conducts a regular teacher job satisfaction survey (see Figure 4) and the principal was encouraged by the results post Leader in Me implementation.

TABLE 4

\section{PRINCIPAL PERCEPTIONS OF GREATER TEACHER COLLABORATION}

\begin{tabular}{|c|}
\hline t in grade levels, but we have \\
\hline $\begin{array}{l}\text { I think before you were in your room and I think more conversation is happening now; } \\
\text { teacher to teacher or teacher to student and student to student, so a lot of synergizing is } \\
\text { happening. }\end{array}$ \\
\hline $\begin{array}{l}\text { The teachers have the same language. Before they used to be fighting, you know, backbiting } \\
\text { and stuff. That has been cut down dramatically because people are starting to look at things } \\
\text { differently. }\end{array}$ \\
\hline Teachers will tell you they feel better. They feel there's more collegiality. \\
\hline $\begin{array}{l}\text { Teacher collaboration. As an administrator [I have been] taking teams of teachers to see } \\
\text { other [Leader in Me] schools. Our teachers have come back just jazzed. }\end{array}$ \\
\hline $\begin{array}{l}\text { I think the biggest change was with how people interacted with one another. So, it focuses } \\
\text { on things like the language, seek first to understand. }\end{array}$ \\
\hline Interactions between individuals are personal and me \\
\hline
\end{tabular}

More Parental Involvement

Schools that had been Leader in Me schools for at least a year or longer noted they were enjoying more parental involvement. More importantly, parents were involved in positive ways, not just coming in to complain or to answer for their child's behavior. Several schools had held or were planning parent nights to teach parents about the 7 Habits. At least two schools had included parents on the lighthouse 
team which helps to oversee the implementation of the Leader in Me process in the school. Having representation from the teachers, the students, and the parents all on one team was showing parents that their voices were important and needed as they worked together to improve the school. Even in the schools where the parents were working multiple jobs to make ends meet for their families, which often eliminated their opportunities to come to the school and participate, the written or phone communication between the school and the parents had improved since implementing the Leader in Me process in their school.

\section{TABLE 5 \\ PRINCIPAL PERCEPTIONS OF MORE PARENTAL INVOLVEMENT}

\begin{tabular}{l} 
Their families can internalize it. They saw it as a lifelong process, not something that's \\
limited to what only teachers teach and students learn. It's a way of living. \\
\hline $\begin{array}{l}\text { Some staff will value that their input is actualized to the community. They really build a } \\
\text { stronger community. }\end{array}$ \\
\hline $\begin{array}{l}\text { We are very urban; our parents are working multiple jobs. We expose them to something } \\
\text { outside of the neighborhood. }\end{array}$ \\
\hline $\begin{array}{l}\text { The process also links organizations across the United States in an effort to help us help } \\
\text { each other. The thing I like most about the Leader in Me process is that it encourages both } \\
\text { the students and the adults to become leaders in their lives. }\end{array}$ \\
\hline $\begin{array}{l}\text { One of the biggest changes that I've seen is that I started to use it in my own house with my } \\
\text { own children. }\end{array}$ \\
\hline
\end{tabular}

Increase in Student Achievement

Principals described the Leader in Me as a way of learning that improved both teacher and student attitudes about learning and respectively led to an increase in student achievement. Being relatively new to the process, some principals mentioned that they felt academic improvements would surely follow due to so many improvements in behavior and attitudes. Every school was in the process of establishing and tracking goals to document their progress.

\section{TABLE 6 PRINCIPAL PERCEPTIONS OF STUDENT ACHIEVEMENT}

\begin{tabular}{l}
\hline $\begin{array}{l}\text { We have seen an increase in student achievement as a result of the goal-setting we have } \\
\text { done with both teachers and students. }\end{array}$ \\
\hline They [teachers] reported a lot of good results so I feel confident. \\
\hline It's that third year where you focus on student-led conferencing and you're starting to see \\
the changes in academics. \\
\hline To actually make movement in test scores or to make movement in any type of data is really, \\
really hard. With the 7 Habits, it's been not perfect but way better. \\
\hline $\begin{array}{l}\text { I think that everything about our school has changed. Students are starting leadership } \\
\text { binders this year [to track their achievement goals.] }\end{array}$ \\
\hline
\end{tabular}

\section{Qualitative Data Findings}

The principal interviews allowed the researchers to hear perceptions and testimonials of the positive results of implementing the Leader in Me. All ten principals had nothing but positive comments concerning the Leader in Me process for their schools. Even when asked if there was anything they did not like about the Leader in Me, not a single comment was made to imply dissatisfaction. The themes and comments were strong and rich. There was a high level of enthusiasm and principals were eager to share their stories of success from the Leader in Me process. 


\section{Quantitative Analysis}

The quantitative data were collected using Hawaii Department of Education public records from School Status and Improvement Reports for each school in the study using math, reading, and science test scores. The test scores were collected for each of the years the ten schools had been involved with the Leader in Me process in math, reading, and science state tests, in addition to 6 years before implementation of the Leader in Me process. Further, twelve years of math, reading, and science test scores were collected from twelve other non-Leader in Me schools. These non-Leader in Me school's data were collected to provide a clearer comparison and analysis of the Leader in Me schools.

\section{Quantitative Data Findings}

Most of the Leader in Me schools did show improvement in their test data, however when comparing the test scores with non-Leader in Me schools, significant increase was not identified. There was a more notable increase in the reading test scores of Leader in Me schools as identified in Figure 1. It was also evident that one school, which had been a Leader in Me school for 11 years and had reached Lighthouse School status, showed the largest increase in both math and science test scores (see Figure 2.) Before becoming a Leader in Me school, their math scores were at 36\% proficiency. Eleven years later, they have risen to $61 \%$. Using an unpaired t-test, both math and reading scores were compared before and after the leadership intervention. Both were statistically significant at a high level of confidence $(p=.0007$ [Math] and .0057 [Reading]). Additionally, their science tests scores rose from $45 \%$ to $81 \%$. As indicated by several other researchers, obtaining Lighthouse status provides more obvious improvement. A study out of the University of North Florida found a $92 \%$ alignment between the practices of the Leader in Me and the proposed best science classroom practices within the Next Generation Science Standards. Given this close alignment, the researchers then analyzed science proficiency rates in Leader in Me schools and found a significant $6.7 \%$ improvement from their pre-Leader in Me performance (Pascale, Ohlson, \& Lee, 2017). A Texas A\&M researcher found that Lighthouse Leader in Me schools performed better on state math and English language arts tests compared to non-Leader in Me schools, as well as, Leader in Me schools that had not reached the level of Lighthouse implementation designation (Leader in Me). Since only one of the ten Leader in Me schools in Hawaii has reached Lighthouse status and seven of the ten schools have only been in the Leader in Me process for less than four years, increased academic results may be too premature to show definitive analysis. However, one of the Hawaiian schools in this study went from $58 \%$ proficiency to $78 \%$ in science. This school has not achieved Lighthouse status yet but has been in the Leader in Me process for four years. 
FIGURE 1

HAWAII STATE TEST SCORES FOR MATH, READING, AND SCIENCE SHOWING 10 YEARS OF DATA
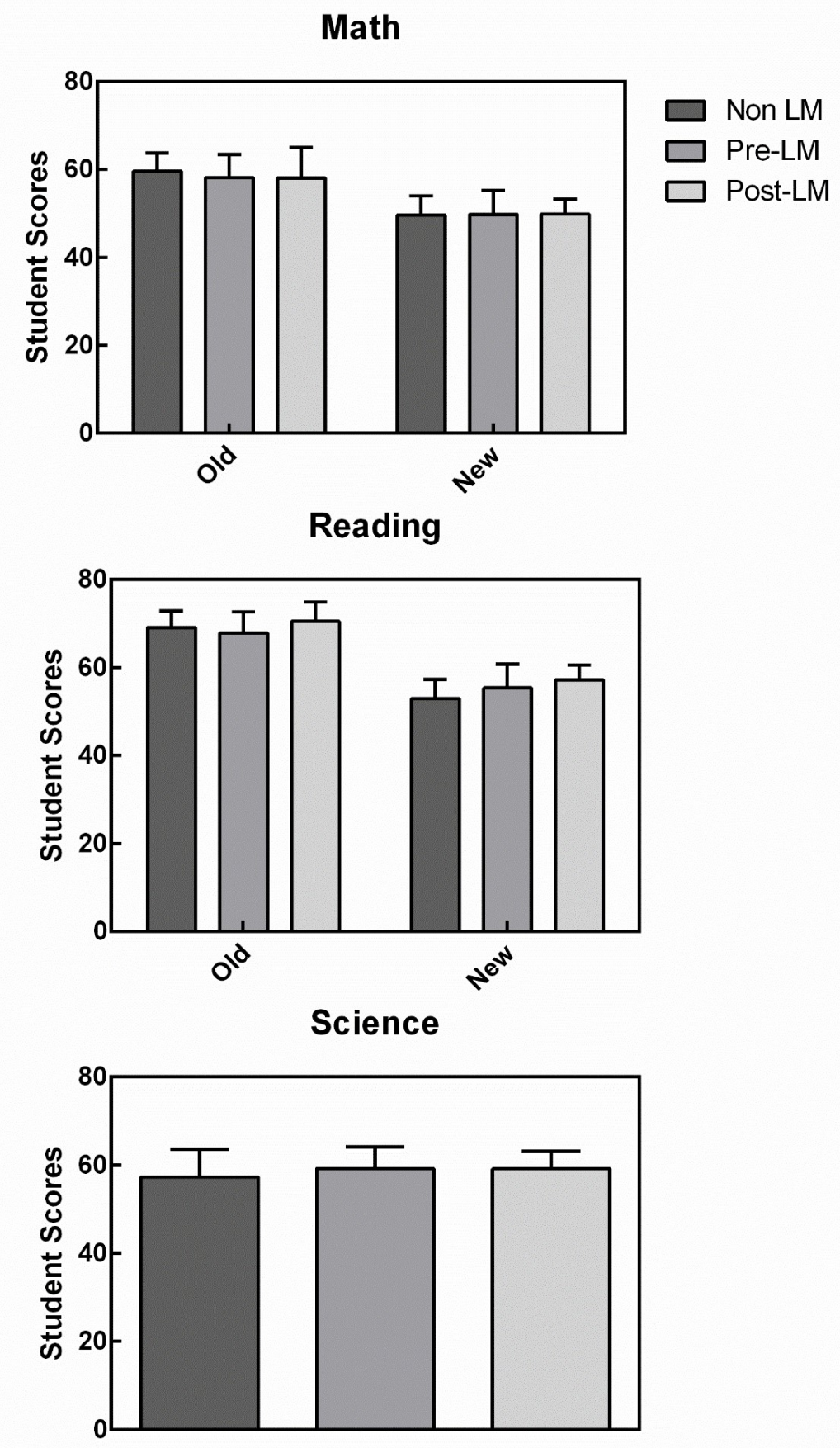

Scores are shown from Non-Leader In Me Schools, as well as Leader In Me schools before (pre) implementing and after (post) implementing The Leader In Me process. The state adopted a new smarter balanced assessment in 20142015. Scores are identified from both old and new tests. The Science test was not changed and the scores are from the same test. Data represent the Mean \pm Standard Error, $N=3$ to 12 Schools. 
FIGURE 2

LIGHTHOUSE SCHOOL TEST SCORES SHOWING 11 YEARS OF DATA

School D Math

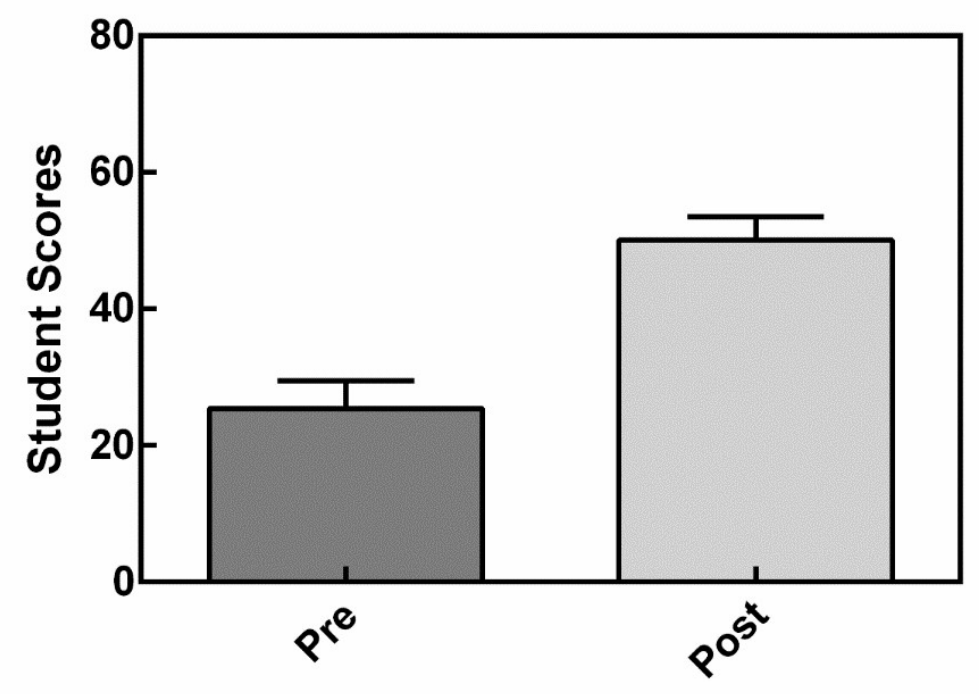

School D Reading

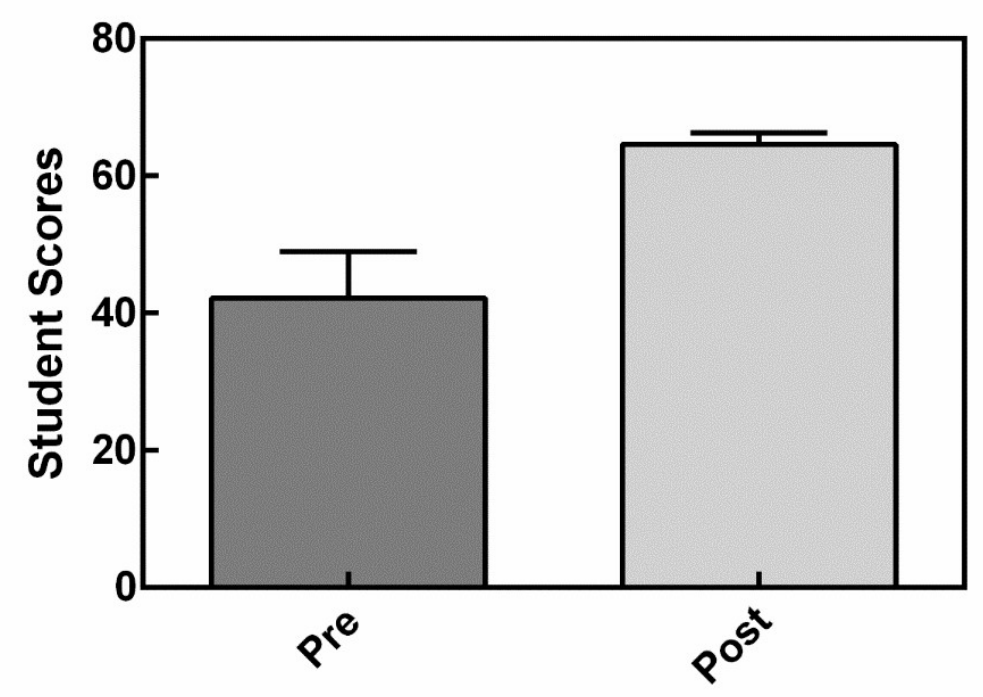

School D Math and Reading scores (same exam) were compared before and after the leadership intervention by TTest (unpaired). The differences before and after the intervention were statistically significant $(\mathrm{P}=.0007$ [Math] and .0057 [Reading]; $\mathrm{N}=6$ [Pre] and 7 [Post]) 
FIGURE 3

SCHOOL B AND SCHOOL C BEHAVIOR REFERRALS WERE COMPARED BEFORE AND AFTER IMPLEMENTING LEADER IN ME

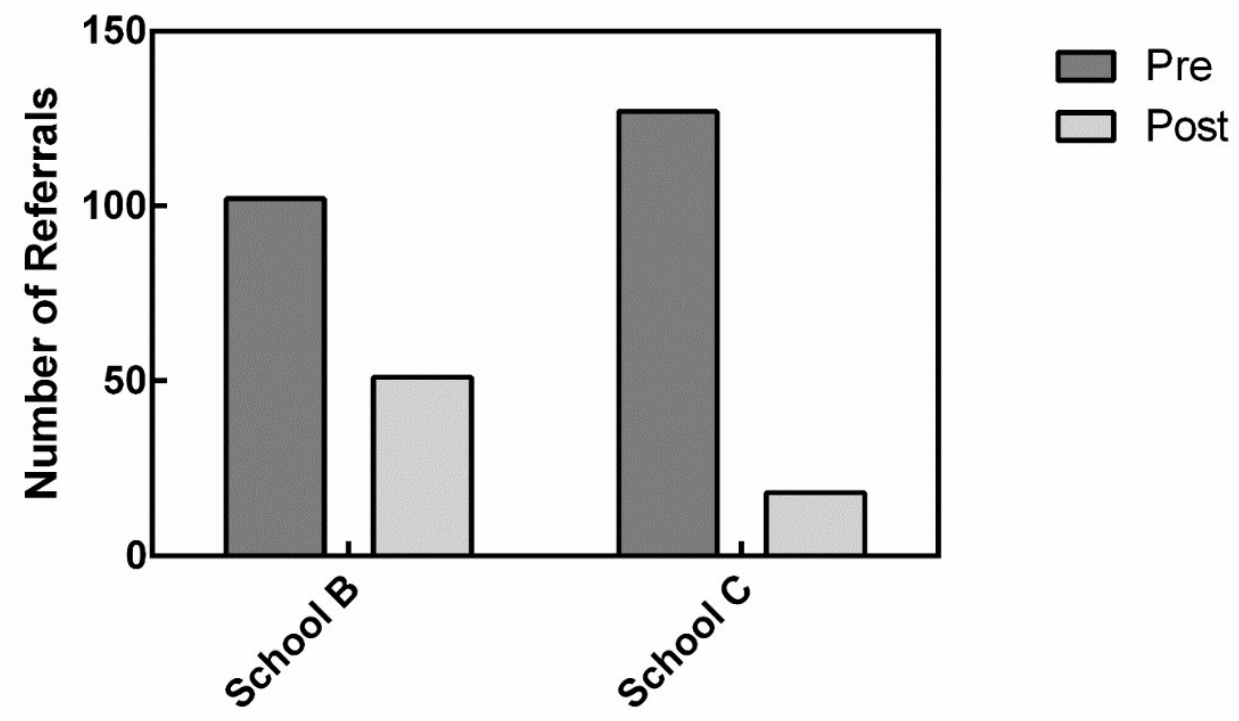

FIGURE 4

TEACHER JOB SATISFACTION SURVEYS WERE COMPARED AT SCHOOL D BEFORE AND AFTER LEADER IN ME IMPLEMENTATION

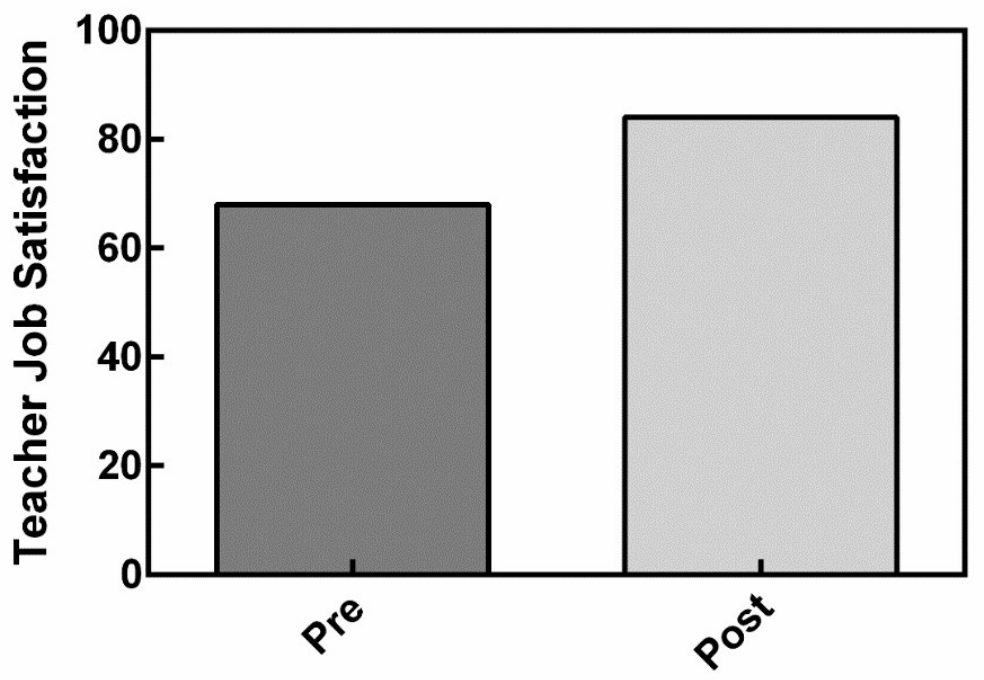

\section{CONCLUSIONS}

Research has indicated the Leader in Me process successful in many schools throughout the United States and several other countries in improving student behavior, increasing communication, raising teacher job satisfaction, and helping to improve academics in some cases. Little research had been conducted to specifically target the Leader in Me schools in the state of Hawaii to identify the impacts. 
This study targeted just Hawaii to discover the impact the Leader in Me has had on the schools involved. Personal interviews and state test data was used to accumulate results for analysis. This study adds to the sparse literature exploring the Leader in Me process impact on schools in Hawaii. The personal interviews with principals provided the richest data for identifying the impact on the schools. Through analyzing the themes, significant indications for school improvement was identified. Teacher satisfaction, greater communication and collaboration, improved student behavior, greater parent involvement, more feelings of empowerment, and positive school environment were all strong indicators. While the state test data did not indicate strong results in academic achievement, individual situations did point to improvements. As has been noted in similar studies, greater time in the Leader in Me process indicates more positive results. Additional research to study the impact over additional years would be helpful.

\section{ACKNOWLEDGEMENTS}

Thanks to Dr. John Bell, Vice President, Brigham Young University-Hawaii, for assistance with statistical data. Thanks to Hannah Kalehuawehe, research assistant, for hours spent collecting test data.

\section{REFERENCES}

Beteille, T., Kalogrides, D., \& Loeb, S. (2012). Stepping stones: Principal career paths and school outcomes. Social Science Research, 41(4), 904-919.

Coffey, S. L. (2018, October 4). Student leadership in the middle years: A matter of concern. SAGE Journals, 14. doi: $10.1177 / 13654802177322$

Cummins, K. (2015, Summer). A Mixed Methods Study on The Leader in Me Process: How Does Fostering Student Leadership Capacity Influence Behavior, Efficacy, and Achievement? Dissertation, 283, 30-50. Retrieved from https://drive.google.com/file/d/1JVwnGykoYd4-HdTUrjJpmpSnvRbar0Ak/view

Darling-Hammond, L. (1998). Teacher learning that supports student learning. Educational Leadership, 55(5), 6-11.

Evans, S. E. (2014). Making Leaders: Examining How Elementary Schools Students Develop an Understanding of Leadership and Show Emerging Leadership Tendencies. Dissertation, 232, 50100. Retrieved from file:///C:/Users/ale/Downloads/Making_leaders_Examining_how_.pdf

Fullan, M. (2010). All systems go: The change imperative for whole system reform. Thousand Oaks, CA: Corwin/Sage Publications.

Humphries, A. C., Cobia, F. J., \& Ennis, L. S. (2015, September). Perceptions of the Leader in Me $C$ Process in Regard to Student Discipline Humphries. Journal of Education and Human Development, 4(3), 93-104.

Ishola, C. M. (2016, August). Key Life Lessons: Learning to Lead Self and Others in Primary School. Dissertation, 203. Retrieved from https://drive.google.com/file/d/1o5J07oJe1cUuEw01mK6x63Z45PBxnYVe/view

Leader in Me - Preparing Students for College and Life. . . (n.d.). Retrieved from www.leaderinme.org

Lynn, A. (2015, April 29). Character in the Classroom: How The Leader in Me Affects Student Performance. Dissertation, 58. Retrieved from http://csusmdspace.calstate.edu/handle/10211.3/138739

Pascale, A., Ohlson, M., \& Lee, J.W. (2017). The habits of highly effective schools: Analyzing the impact of "Leader in Me" schools in Florida. FATE Journal, V2(1).

Patterson, E. (2018, February 6). New University of Michigan studies offer strongest empirical evidence of Leader in Me's effectiveness to date. Retrieved from https://www.leaderinme.org/blog/newuniversity-michigan-studies-offer-strongest-empirical-evidence-leader-mes-effectiveness-date/

Schilling, S. (2018, January 16.) A Quasi-Experimental Study of the Effect of the Leader in Me School Intervention on Discipline Incidents in Florida Schools. Study of LIM School Intervention on 
Discipline in Florida Schools, 15. Retrieved from

https://drive.google.com/file/d/11MqHJO4vDeb5TZaa9I968YBptqhFzaBu/view

Simonsen, B., Sugai, G., \& Negon, M. (2008). School wide positive behavior supports. Teaching Exceptional Children, 4(6), 32-40.

Tidd, C. (2016). Staff perceptions of the effect of the leader in me on student motivation and peer relationships in elementary school (Order No. 10241850). Available from ProQuest Dissertations $\&$ Theses Global; Social Science Premium Collection. (1884639014). Retrieved from https://search. proquest.com/docview/1884639014?accountid=9816

Unal, H., \& Cukur, C. (2011). The Effects of School Bonds, Discipline Techniques in School and Victimization on Deliquency of High School Students. Educational Sciences: Theory and Practice, 11(2), 560-570.

Warren, J. S., Bohanon-Edmonson, H. M., Turnbull, A. P., Sailor, W., Wickham, D., Griggs, P., \& Beech, S. E. (2006). School-wide positive behavior support: Addressing behavior problems that impede student learning. Educational Psychology Review, 18, 187-198.

Waters, T., Marzano, R. J., \& McNulty, B. (2003). Balanced Leadership: What 30 Years of Research Tells Us about the Effect of Leadership on Student Achievement. A Working Paper. Dissertation, 21. Retrieved from https://eric.ed.gov/?id=ED481972

White, M. (2018, January 24). A Quasi-Experimental Study of the Effect of the Leader in Me on Attendance and Discipline in Missouri Schools. Dissertation, 13. Retrieved from https://drive.google.com/file/d/1iiGq1RKKFyPC39QFuQdcjgjmNyxhmaIq/view

Wilkens, C. L., \& Wilmore, E. (2015, March). Does Implementing an Emotional Intelligence Program Guarantee Student Achievement? Education Leadership Review of Doctoral Research, v2(n1), 34-46. 